\title{
Recycling of Waste MDF by Steam Refining: Evaluation of Fiber and Paper Strength Properties
}

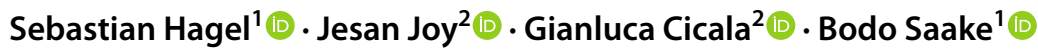

Received: 28 October 2020 / Accepted: 10 February 2021 / Published online: 24 February 2021

(C) The Author(s) 2021

\begin{abstract}
Currently, most of the collected waste medium-density fiberboards (MDF) is incinerated or landfilled, as economically viable recycling methods are yet to be developed. By steam refining waste medium-density fiberboards (MDF), it is possible to hydrolyze the incorporated resins and isolate a high yield fiber fraction. Further refining of the steam treated fibers might enable the fibers to be utilized in applications such as paper packaging, facilitating a cascading use of the waste material stream. To this end, intimate knowledge of the material is needed. In this study, the steam refined fibers of two waste MDF samples containing differing amounts of softwood and hardwood underwent refining and beating. The resulting fibers were characterized regarding their morphology and paper test sheets were produced to evaluate their strength (compression-, tensile- and tear-strength). Distinct differences in response to refining between the MDF samples were apparent. For the sample with the higher hardwood share an increase in strength properties with increasing steam treatment severities could be observed and it was possible to produce test sheets with comparable compression strength to recycled pulp for industrial corrugated paperboard. For the sample with a higher share of softwood, the steam treatment severity did not show any influence on fiber morphology or paper properties, and the resulting paper strength was low in comparison to the other steam refined waste MDF sample.
\end{abstract}

\section{Graphic Abstract}

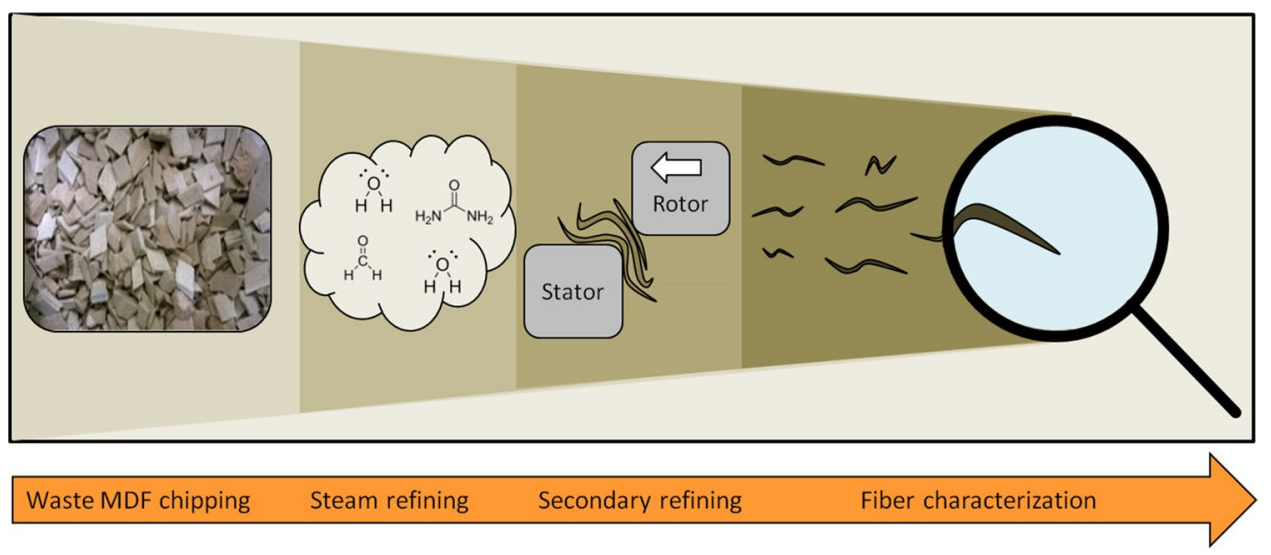

Keywords Waste MDF $\cdot$ Biomass residues $\cdot$ Recycling $\cdot$ Steam treatment $\cdot$ Fibers $\cdot$ Added value products

Bodo Saake

Bodo.Saake@uni-hamburg.de

Extended author information available on the last page of the article

\section{Statement of Novelty}

As there currently is no widely deployed recycling method for waste MDF, the utilization of steam to fractionate waste MDF in the context of a bio refinery, in which all parts of 
the material are processed, might prove a viable recycling concept to fill this void. The fiber fraction represents the major share of the material after the steam treatment, and finding an economic and ecological application for the fibers will be a key element in successful valorization. Because the amount of waste MDF and the demand for fiber based packaging solutions is steadily rising, a deployment of the steamed fibers in packaging applications could be a step in solving both challenges simultaneously. Thus, an investigation into the fiber and resulting paper properties was undertaken to identify problems and evaluate the viability of the concept.

\section{Introduction}

Medium density fiberboards (MDF) are an engineered wood product made out of lignocellulosic fibers, which are blended with resins and hot-pressed into panel shape $[1,2]$. Roughly $80 \%$ of the manufactured panels are processed further into furniture or flooring applications [3]. Due to the rising demand, the worldwide production volume of MDF has increased continuously, from roughly 8 million $\mathrm{m}^{3}$ in 1995 to almost 100 million $\mathrm{m}^{3}$ in 2018 [4]. At the same time, shifts in consumer behavior, such as the perception of furniture as a fashion item instead of a durable commodity, have led to increasingly shorter life cycles [5]. Consequently, a rising amount of waste MDF is accumulating. Assuming an average life span of approximately 14 years, a total waste MDF volume of almost 50 million $\mathrm{m}^{3}$ can be calculated just for the year 2016 [6]. In Europe, due a combination of factors such as government subsidies, challenges in sorting of the waste material stream and stability of the waste material supply chain, a major part of the available waste wood is incinerated for energy generation [7]. Following the principles laid out in the Waste Framework Directive of the European Parliament [8], a material recycling should always be given priority over energy recovery or land filling, as by reusing the material before energy recovery, the biomass can be used in a cascade, improving the resource efficiency [9].

Fractionation is a necessary step to enable a material recycling of waste MDF. Using hydrothermal or steam-based treatments it is possible to hydrolyze the urea-formaldehyde (UF) based resins [10-14], which make up the majority of the resins used in MDF production [15]. To compare chemical and structural changes in differing steam-based treatments of lignocellulosic material, the severity factor, which combines the two main process parameters treatment duration and temperature, can be used [16, 17]. In a previous study steam refining was used to fractionate standard waste MDF, the applicability of the severity factor in steaming of waste MDF was confirmed and the influence of differing treatment severities on the chemical composition of the fractions and the process was evaluated [18]. By steam refining of waste MDF a liquid and a solid fraction is generated. The liquid fraction contains solubilized carbohydrates and lignin as well as a high amount of nitrogen and acids (acetic and formic). The $\mathrm{pH}$ of the liquid extract of around 8 is high in comparison to liquid fractions of steam treated native lignocellulosic material, due to a high amount of ammonium hydroxide following the degradation of the urea-formaldehyde resins $[12,13]$. As the fiber fraction accounts for the major fraction after the steam refining treatment, the development of an economically viable recycling pathway for the fibers is of prime interest for the advancement of material recycling of waste MDF.

The reuse of the separated waste MDF fibers in production of new MDF is the most apparent possible recycling pathway. However, due to a combination of effects such as fiber shortening, changes in the chemical compositions of the fibers and resin residues found on their surface, a deterioration of the mechanical properties in comparison with MDF made from fresh wood can be observed when using hydrothermal or steam-based fractionation processes [19-24]. Recently, Moezzipour et al. [25] have reported that such negative effects on the fibers can be reduced using electrical heating instead of hydrothermal treatments, leading to improved mechanical properties of the newly produced MDF. Other previously investigated potential uses for recovered waste MDF include the production of cellulose nanocrystals [26, 27], wood polymer composites (WPC) [28-30], bio-ethanol [31-33], bio-oil and biogas [34-37], or the substitution of particles in the middle layer of particle boards [38] as well as insulation or oil spill absorbance applications [39].

Another potential recycling path might be the utilization of steam refined waste MDF fibers in paper packaging applications, such as corrugated boards, allowing for extended cascading of the wood fibers. Corrugated board is the packaging material with the highest production volume worldwide [40] and due to the continuing increase in e-commerce, the demand is expected to remain high even in times of uncertain global trade relations [41]. Corrugated board consists of at least one wave-like element called flute and one flat sheet called liner or linerboard [42]. The overall structure of a corrugated board is making use of the engineering beam principle, in which the fluting acts as a supporting structure for the two load-bearing planes. As hardwood fibers are shorter and stiffer than softwood fibers, which makes the papers easy to corrugate but still gives them a rigid structure, the flute is usually made from recycled pulp or from virgin hardwood neutral sulphite semi-chemical pulp. The flat liners are called test liner if manufactured from recycling fibers, or kraft liner if manufactured out of virgin softwood kraft pulps [40]. In Germany, $65 \%$ of all packaging material for transportation is made out of corrugated board and 
$80 \%$ of the produced corrugated board is manufactured with recycling fibers [43]. As a result of limitations in available forest-based materials [44] and growing environmental awareness of the population, the corrugated board industry is utilizing recycling fibers to an increasing degree, which, from an environmental point of view, can be considered a benefit due to reduced emission of $\mathrm{CO}_{2}$ [45]. However, the recycling process causes a deterioration of the mechanical properties of the fibers, which can lead to a strength loss of up to $30 \%$ of its original strength [46]. The passage of the fibers through the recycling chain (which includes repeated drying, printing, converting, storing, deinking and re-refining) leads to hornification, a reduction of cell wall porosity, fiber shortening, loss of flexibility, re-adhesion of fibrils onto the fiber surface, micro-indentations and -compressions, loss of degree of polymerization, self-sizing, loss of hemicelluloses on the fibers surface and the accumulation of contaminants, all of which can have a negative impact on the paper strength [46-51]. One potential way of mitigating the effect of the deteriorating quality of the recycled fibers available is the introduction of new fibers into the production process, such as wheat straw pulp $[52,53]$.

Thus, to converge the afore mentioned challenges of the large quantities of waste MDF to be disposed of, the high demand of fibrous material for the packaging industry, and the deteriorating quality of the recycled pulp, this study aims to assess the viability of utilizing steam refined fibers from post-consumer MDF in recycled paper packaging as filler or reinforcement material. Currently, most MDF in European countries is produced from softwood. As a shift in forest management is leading to a reduction of softwood stands and an increase in hardwood stands in Europe [54], the resulting shortage of softwood and oversupply of hardwood will likely push the MDF manufacturers to increase the amount of hardwood utilized. To take this development into account, a waste MDF sample set containing a high amount of hardwood and one containing a high amount of softwood were used and compared to each other and to recycled fibers used in the industry for manufacturing of corrugated board. The waste MDF samples were treated at six different severity grades, ranging from 2.5 to 4.0 . In a previous publication the effect of steam refining on the reactions of chemical components was reported [18]. In the present paper the effect of steaming severity and refining intensity on fiber morphology and strength properties will be evaluated. As the gap between the rotating blades and the inner wall of the steam refining reactor is large (10 to $20 \mathrm{~mm}$ ) in comparison to typical fiber dimensions ( 0.6 to $4.4 \mathrm{~mm}$ length and 10 to $50 \mu \mathrm{m}$ diameter [55]), the steam treated waste MDF fibers are present in small fiber bundles [18]. A secondary refining and beating was performed on the steam refined fibers to separate the fiber bundles and improve the fiber properties for papermaking. In refining and beating, flocs and fibers are deformed in the presence of water by two metallic surfaces moving in relation to each other, causing compressive and shear forces in the pulp. The main positive effects on the fibers are an external and internal fibrillation as well as the formation of fines, leading to an increase of surface area available for fiber to fiber bonding [56-58]. The resulting pulp was characterized using an automated fiber length analyzer and used for test sheet preparation. The tensile-, compression-, and tear-strength, as well as brightness of the test sheets were measured and the relationship between the fiber morphology and paper strength evaluated.

\section{Material and Methods}

\section{Raw Material and Their Preparation}

Two chipped, clean waste MDF samples without lamination supplied by École supérieure du bois (Nantes, France) were used in this study. The chipped waste MDF featured a length of roughly 10 to $50 \mathrm{~mm}$, a width of $15 \mathrm{~mm}$ and a height of around $10 \mathrm{~mm}$. Batches of $300 \mathrm{~g}$ (dry matter) waste MDF chips were steam treated in a 10-1 reactor with a diameter of $22 \mathrm{~cm}$ and a length of $25 \mathrm{~cm}$ (Martin Busch \& Sohn GmbH, Germany) at severities ranging from 2.5 to 4 . The severity ( $\log \mathrm{R}_{0}$ ) of the steam treatments was calculated according to Eq. (1). In the last $30 \mathrm{~s}$ of the treatment, the fibers were defibrated within the steam filled reactor by rotation of a built-in four bladed system at a speed of $1455 \mathrm{rpm}$.

$\log R_{0}=\log \left(t \times e^{\frac{(T-100)}{14,75}}\right)$

with T: steam temperature in ${ }^{\circ} \mathrm{C}$, t: steaming duration in min.

At the end of the treatment duration, the steam was released through a valve in about $90 \mathrm{~s}$. Subsequently, the fiber fraction was separated from the extract by filtration through a sieve bag and dewatered for $10 \mathrm{~min}$ at $2800 \mathrm{rpm}$ in a spin dryer (Thomas Centri 776 SEK, Thomas, Germany). The fiber fraction was passed through a 12" Sprout-Bauer laboratory refiner (Andritz, Graz, Austria) three times. In the first pass, the gap distance was adjusted to $0.5 \mathrm{~mm}$ and the consistency of the pulp was adjusted to $4 \%$. In the following two passes, the gap distances were reduced to $0.2 \mathrm{~mm}$ and the consistency decreased continuously due to the addition of rinsing water to a final consistency of around $2 \%$. The fibers were separated from the rinsing water using above mentioned procedure. The complete process is depicted in Fig. 1.

In Table 1 the chemical composition of the two waste MDF samples and the fibers after steaming are presented. Detailed information regarding the determination of the chemical composition of the samples, as well as a discussion on the process reactions is given in a previous 
Fig. 1 Process flowchart

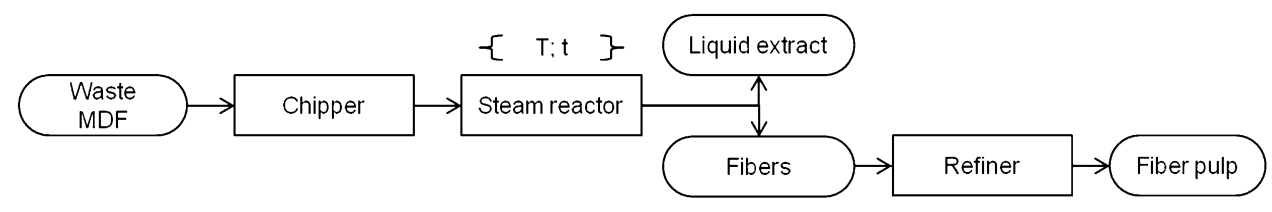

Table 1 Chemical composition of the waste MDF samples (untreated) and after steaming refining in [\%] $\mathrm{w} / \mathrm{w}[18]$

\begin{tabular}{lllllll}
\hline Sample & $\begin{array}{l}\text { Severity } \\
\left(\log \mathrm{R}_{0}\right)\end{array}$ & $\begin{array}{l}\text { Glucose } \\
(\%)\end{array}$ & $\begin{array}{l}\text { Xylose } \\
(\%)\end{array}$ & $\begin{array}{l}\text { Mannose } \\
(\%)\end{array}$ & $\begin{array}{l}\text { Lignin } \\
(\%)\end{array}$ & $\begin{array}{l}\text { Nitrogen } \\
(\%)\end{array}$ \\
\hline SR-MDF (A) & Untreated & 38.3 & 12.4 & 4.0 & 24.4 & 4.2 \\
& 2.5 & 42.3 & 14.0 & 4.3 & 27.3 & 1.2 \\
& 2.8 & 42.7 & 14.0 & 4.3 & 26.5 & 1.2 \\
& 3.1 & 43.0 & 13.2 & 4.5 & 26.6 & 0.9 \\
& 3.4 & 44.2 & 12.6 & 4.2 & 27.2 & 0.9 \\
& 3.7 & 45.6 & 10.7 & 4.7 & 30.0 & 1.1 \\
& 4.0 & 48.2 & 8.0 & 4.6 & 32.9 & 1.2 \\
SR-MDF (B) & Untreated & 37.6 & 5.7 & 7.2 & 26.6 & 4.4 \\
& 2.5 & 46.8 & 7.0 & 8.6 & 31.6 & 1.1 \\
& 2.8 & 46.7 & 6.8 & 8.4 & 32.1 & 1.1 \\
& 3.1 & 46.5 & 6.5 & 8.4 & 33.1 & 1.1 \\
& 3.4 & 48.5 & 6.2 & 8.7 & 32.6 & 1.1 \\
& 3.7 & 50.4 & 5.5 & 8.8 & 33.7 & 1.0 \\
& 4.0 & 49.6 & 4.4 & 8.1 & 35.3 & 1.1 \\
\hline
\end{tabular}

publication [18]. In the first sample (SR-MDF A) a higher amount of xylose (12.4\%), a lower amount of mannose $(4.0 \%)$ and a lower amount of lignin $(24.4 \%)$, than in the second sample (SR-MDF B) with 5.7\%, 7.2\% and 26.6\%, respectively, was determined. The high proportion of xylose with only small amount of mannose is characteristic for hardwood [55]. This indicates that a high amount of hardwood was used in the manufacturing of the first sample. In contrast to that the proportion of mannose and xylose in SR-MDF B shows a slight preference for mannose which is characteristic for softwood, indicating a dominance of softwood fibers in this sample. The nitrogen content of both samples were found to be similar, indicating a similar amount of UF-resin used in production. Due to a high amount of extractable resin at a low severity treatment of 2.5, which can be seen in the changes to the nitrogen content, the fiber yield of the steam treated waste MDF fibers drops and the amount of glucose, xylose, mannose and lignin rises in relation to the raw material. An increasing solubilization of the hemicelluloses following an increase in treatment severity leads to a further increase in fiber yield and consequently, the relative content of lignin and glucose rises. For comparison of the fiber morphology and test paper strength, recycling pulp from two different industrial corrugated paperboard producers was evaluated alongside the SR-MDF samples. The recycled pulp (RP) samples were taken after sorting, shortly ahead of the headbox.

\section{Pulp and Fiber Characterization}

All samples were subjected to additional beating in a Jokro mill (FRANK-PTI, Birkenau, Germany) following the procedure described in DIN 54360:2004 [59]. Subsequently, the pulp suspensions were disintegrated according to ISO 52632:2004 [60] for $2 \mathrm{~min}$. Unbeaten samples were disintegrated for $20 \mathrm{~min}$. For representative sampling, the disintegrated pulp was kept in constant movement in a laboratory equalizer until further processing. The beating degree was measured in a Schopper-Riegler freeness tester type SR1 (Karl Schröder KG, Weinheim, Germany) according to ISO 52671:1999 [61]. For fiber morphology characterization, samples of the pulp were analyzed using a kajaaniFiberLab (Metso, Helsinki, Finland). The arithmetic average fiber length L(n) and the length weighted fiber length $\mathrm{L}(\mathrm{lw})$ were calculated according to Eqs. 2 and 3, respectively. A high amount of fine material will significantly affect the arithmetic mean, while having a lower influence on the length weighted fiber length. The fiber width was calculated analogous to the arithmetic fiber length $\mathrm{L}(\mathrm{n})$, using the width of the fibers. The average fiber Curl(n) was calculated according to Eq. 5 . The average kink index Kink(n) was calculated according to Eq. 7. 
$\mathrm{L}(\mathrm{n})=\frac{\sum\left(\mathrm{n}_{\mathrm{i}} \mathrm{l}_{\mathrm{i}}\right)}{\sum \mathrm{n}_{\mathrm{i}}}$

$\mathrm{L}(\mathrm{lw})=\frac{\sum\left(\mathrm{n}_{\mathrm{i}} \mathrm{l}_{\mathrm{i}}^{2}\right)}{\sum \mathrm{n}_{\mathrm{i}}}$

$n_{i}=$ number of fibers in the specified fiber class, $l_{i}=$ fiber length in specified class [mm]

$\operatorname{Curl}_{\mathrm{i}}=\left(\frac{\mathrm{Lc}_{\mathrm{i}}}{\mathrm{Lp}_{\mathrm{i}}}-1\right) * 100 \%$

$\operatorname{Curl}(\mathrm{n})=\frac{\sum\left(\mathrm{n}_{\mathrm{i}} * \operatorname{Curl}_{\mathrm{i}}\right)}{\sum \mathrm{n}_{\mathrm{i}}}$

$\mathrm{Lc}_{\mathrm{i}}=$ true contour fiber length $[\mathrm{mm}], \mathrm{Lc}_{\mathrm{p}}=$ projected fiber length $[\mathrm{mm}], \mathrm{Curl}_{\mathrm{i}}=$ Fiber curl of specified fiber class [\%]

$\operatorname{Kink}_{\mathrm{i}}=\frac{\left(\mathrm{n}_{10-20^{\circ}}+2 * \mathrm{n}_{21-45^{\circ}}+3 * \mathrm{n}_{46-90^{\circ}}+4 * \mathrm{n}_{90+^{\circ}}\right)}{\mathrm{Lc}_{\mathrm{i}}}$

$\operatorname{Kink}(\mathrm{n})=\frac{\sum\left(\mathrm{n}_{\mathrm{i}} * \mathrm{Kink}_{\mathrm{i}}\right)}{\sum \mathrm{n}_{\mathrm{i}}}$

$\mathrm{n}_{\mathrm{x}-\mathrm{y}}=$ Numbers of kinks with a kink angle between $\mathrm{x}^{\circ}$ to $\mathrm{y}^{\circ}$, $\mathrm{Kink}_{\mathrm{i}}=$ Number of kinks of specified fiber class [1/mm].

Laboratory paper sheets of about $75 \mathrm{~g} / \mathrm{m}^{2}$ were produced with a Rapid-Köthen sheet forming machine (FRANK-PTI, Birkenau, Germany) as described by ISO 5269-2:2004 [62] and conditioned for at least $24 \mathrm{~h}$ at $(23 \pm 1){ }^{\circ} \mathrm{C}$ and $(55 \pm 2) \%$ relative humidity before physical testing. The brightness was measured according to TAPPI T525 [63] with an ELREPHO 450X from Datacolor (Rotkreuz, Switzerland). The short span compressive (SCT) strength was measured according to DIN 54518:2004 [64], the tensile strength according to ISO 1924-2:2009 [65] and the tear strength according to ISO 1974:2012-09 [66]. All instruments used for aforementioned measurements were manufactured by FRANK-PTI Gmbh (Birkenau, Germany). The indices were calculated according to TAPPI T 220 [67].

\section{Results and Discussion}

\section{Fiber Morphology}

Key parameters of the fiber morphology of the waste MDF fibers following steam refining treatments of different severity are presented in Table 2 and compared to recycled pulp samples from industrial corrugated paperboard producers. The SR-MDF (B) fibers show widths of $30.1 \mu \mathrm{m}$ to $31.8 \mu \mathrm{m}$ and length weighted fiber lengths of $0.87 \mathrm{~mm}$ to $1.00 \mathrm{~mm}$ in comparison to widths of $24.1 \mu \mathrm{m}$ to $25.0 \mu \mathrm{m}$ and length weighted lengths of $0.72 \mathrm{~mm}$ to $0.86 \mathrm{~mm}$ of the SR-MDF (A) fibers. These differences support the presumption of the different ratios of softwood and hardwood fibers in the corresponding samples, as softwood fibers are usually longer and wider than hardwood fibers [55, 68].

A more severe steam treatment led to a slight reduction in fiber length, while the fiber width and the amount of fines material was mostly unaffected for both SR-MDF sample sets. However, differences in behavior between the SR-MDF sample A and B can be seen in the amount of fiber kink and curl measured. While the amount of fiber curl and kinks were mostly unaffected for the SR-MDF (B) sample, except for a slight increase at the very highest severity degree, a distinct increase in fiber curl and kinks can be observed for
Table 2 Influence of the treatment severity on the fiber morphology of the steam treated waste MDF samples in comparison to morphological characteristics of recycled pulp

\begin{tabular}{|c|c|c|c|c|c|c|c|c|}
\hline Sample & & $\begin{array}{l}\text { Severity } \\
\left(\log R_{0}\right)\end{array}$ & $\begin{array}{l}\mathrm{L}(\mathrm{n}) \\
(\mathrm{mm})\end{array}$ & $\begin{array}{l}\mathrm{L}(\mathrm{lw}) \\
(\mathrm{mm})\end{array}$ & $\begin{array}{l}\text { Width } \\
(\mu \mathrm{m})\end{array}$ & $\begin{array}{l}\text { Fines } \\
(\%)\end{array}$ & $\begin{array}{l}\text { Fiber Curl } \\
(\%)\end{array}$ & $\begin{array}{l}\text { Kink index } \\
(1 / \mathrm{m})\end{array}$ \\
\hline \multirow[t]{6}{*}{ SR-MDF } & (A) & 2.5 & 0.54 & 0.86 & 25.0 & 5.0 & 6.2 & 356 \\
\hline & & 2.8 & 0.46 & 0.75 & 24.7 & 8.0 & 6.2 & 306 \\
\hline & & 3.1 & 0.47 & 0.76 & 24.2 & 7.1 & 6.9 & 365 \\
\hline & & 3.4 & 0.49 & 0.78 & 25.0 & 6.5 & 7.4 & 434 \\
\hline & & 3.7 & 0.48 & 0.76 & 24.8 & 6.7 & 10.0 & 603 \\
\hline & & 4.0 & 0.46 & 0.72 & 24.1 & 6.9 & 11.4 & 723 \\
\hline \multirow[t]{6}{*}{ SR-MDF } & (B) & 2.5 & 0.56 & 0.96 & 30.3 & 5.4 & 5.2 & 296 \\
\hline & & 2.8 & 0.55 & 1.00 & 30.1 & 6.1 & 5.0 & 241 \\
\hline & & 3.1 & 0.56 & 0.96 & 31.6 & 5.3 & 4.8 & 265 \\
\hline & & 3.4 & 0.53 & 0.95 & 30.9 & 6.3 & 5.0 & 256 \\
\hline & & 3.7 & 0.50 & 0.93 & 30.8 & 7.8 & 5.3 & 269 \\
\hline & & 4.0 & 0.50 & 0.87 & 30.1 & 6.7 & 5.9 & 381 \\
\hline $\mathrm{RP}$ & $\# 1$ & - & 0.53 & 1.09 & 22.1 & 5.3 & 20.1 & 1528 \\
\hline $\mathrm{RP}$ & $\# 2$ & - & 0.55 & 1.09 & 20.7 & 5.1 & 16.9 & 1062 \\
\hline
\end{tabular}


the SR-MDF (A) sample following an increase in treatment severity. In comparison to the recycled pulp samples, the SR-MDF fibers are shorter and wider, show less fiber curling and a lower amount of kinks.

Following the refining, all of the SR-MDF samples were beaten for an additional 20, 40 and 60 min to evaluate the influence of the treatment severity on the length and width of the steam refined waste MDF fibers and the resulting test paper strengths over a wide range of beating degrees. In Table 3 the measured fiber lengths and widths are presented.

In all samples the fiber width increased and the fiber length decreased with beating time, irrespective of treatment severity. After 60 min of beating, a fiber width increase of roughly $10 \%$ can be measured. The width increase can be explained with a flattening of the fibers due to a collapse of the lumen in beating [48]. While the arithmetic average fiber lengths of the SR-MDF (A) and SR-MDF (B) sample do not differ much, considerable differences in the length weighted fiber lengths are visible. This implicates differences in the amount of short fiber fragments and therefore the fiber length distribution between the two samples. In Fig. 2, the length-weighted fiber length distribution for the lowest and highest severity treatments of both samples is presented. A clear shift in fiber length distribution to the lower lengths following an increased beating duration is visible. For the SR-MDF (B) sample, the severity of the steam treatment did not seem to significantly alter the general reduction in fiber length as a function of beating duration. For the SR-MDF (A) fiber samples on the other hand, an increase in treatment severity led to a reduction in the small fiber population after prolonged beating, which is reflected in the increase of the $\mathrm{L}(\mathrm{lw})$ at more severe treatments and high beating durations. Without additional beating, the treatment severity had the opposite influence, and the highest length weighted fiber length could be determined at the lower severities. This is reflected in the higher amount of fibers found at a length of $1.5 \mathrm{~mm}$ and longer after low severity treatments.

\section{Influence of Treatment Severity on the Development of the Beating Degree}

In Fig. 3 the beating degree of the different samples as a function of the beating time is presented. The beating degree is a measurement of the drainability of a fiber web and an
Table 3 Influence of the beating duration on the arithmetic average fiber length $\mathrm{L}(\mathrm{n})$, the length weighted fiber length $\mathrm{L}(\mathrm{lw})$ and the fiber width of the SR-MDF samples

\begin{tabular}{|c|c|c|c|c|c|c|c|}
\hline \multirow{2}{*}{$\begin{array}{l}\text { Treatment severity } \\
\left(\log \mathrm{R}_{0}\right)\end{array}$} & \multirow{2}{*}{$\begin{array}{l}\text { Beating duration } \\
\text { (min) }\end{array}$} & \multicolumn{3}{|c|}{ SR-MDF (A) } & \multicolumn{3}{|c|}{ SR-MDF (B) } \\
\hline & & $\begin{array}{l}\mathrm{L}(\mathrm{n}) \\
(\mathrm{mm})\end{array}$ & $\begin{array}{l}\mathrm{L}(\mathrm{lw}) \\
(\mathrm{mm})\end{array}$ & $\begin{array}{l}\text { Width } \\
(\mu \mathrm{m})\end{array}$ & $\begin{array}{l}\mathrm{L}(\mathrm{n}) \\
(\mathrm{mm})\end{array}$ & $\begin{array}{l}\mathrm{L}(\mathrm{lw}) \\
(\mathrm{mm})\end{array}$ & $\begin{array}{l}\text { Width } \\
(\mu \mathrm{m})\end{array}$ \\
\hline \multirow[t]{4}{*}{2.5} & 0 & 0.54 & 0.86 & 25.0 & 0.56 & 0.96 & 30.3 \\
\hline & 20 & 0.33 & 0.53 & 25.0 & 0.37 & 0.65 & 31.1 \\
\hline & 40 & 0.21 & 0.31 & 26.9 & 0.23 & 0.37 & 33.4 \\
\hline & 60 & 0.18 & 0.26 & 27.8 & 0.18 & 0.28 & 34.4 \\
\hline \multirow[t]{4}{*}{2.8} & 0 & 0.46 & 0.75 & 24.7 & 0.55 & 1.00 & 30.1 \\
\hline & 20 & 0.26 & 0.42 & 25.6 & 0.41 & 0.71 & 32.2 \\
\hline & 40 & 0.21 & 0.31 & 26.8 & 0.23 & 0.36 & 33.8 \\
\hline & 60 & 0.18 & 0.26 & 27.4 & 0.20 & 0.31 & 33.6 \\
\hline \multirow[t]{4}{*}{3.1} & 0 & 0.47 & 0.76 & 24.2 & 0.56 & 0.96 & 31.6 \\
\hline & 20 & 0.27 & 0.43 & 24.9 & 0.31 & 0.51 & 32.5 \\
\hline & 40 & 0.21 & 0.31 & 26.5 & 0.22 & 0.34 & 34.6 \\
\hline & 60 & 0.19 & 0.28 & 27.7 & 0.18 & 0.28 & 34.3 \\
\hline \multirow[t]{4}{*}{3.4} & 0 & 0.49 & 0.78 & 25.0 & 0.53 & 0.95 & 30.9 \\
\hline & 20 & 0.28 & 0.43 & 25.1 & 0.31 & 0.50 & 31.8 \\
\hline & 40 & 0.23 & 0.34 & 26.3 & 0.23 & 0.34 & 33.7 \\
\hline & 60 & 0.21 & 0.30 & 26.9 & 0.20 & 0.29 & 34.6 \\
\hline \multirow[t]{4}{*}{3.7} & 0 & 0.48 & 0.76 & 24.8 & 0.50 & 0.93 & 30.8 \\
\hline & 20 & 0.34 & 0.53 & 25.2 & 0.34 & 0.55 & 31.8 \\
\hline & 40 & 0.28 & 0.42 & 25.8 & 0.25 & 0.39 & 33.1 \\
\hline & 60 & 0.25 & 0.37 & 27.4 & 0.20 & 0.29 & 33.2 \\
\hline \multirow[t]{4}{*}{4.0} & 0 & 0.46 & 0.72 & 24.1 & 0.50 & 0.87 & 30.1 \\
\hline & 20 & 0.34 & 0.52 & 24.6 & 0.29 & 0.47 & 31.7 \\
\hline & 40 & 0.28 & 0.44 & 26.2 & 0.21 & 0.33 & 32.8 \\
\hline & 60 & 0.25 & 0.39 & 25.9 & 0.18 & 0.28 & 33.3 \\
\hline
\end{tabular}


Fig. 2 Length-weighted fiber length distribution of SR-MDF A (upper row) and SR-MDF $\mathrm{B}$ (bottom row) treated at a severity of 2.5 (left column) and 4.0 (right column) in relation to beating duration
Fig. 3 Relationship between beating duration and beating degree of a SR-MDF (A) and $\mathbf{b}$ SR-MDF (B)
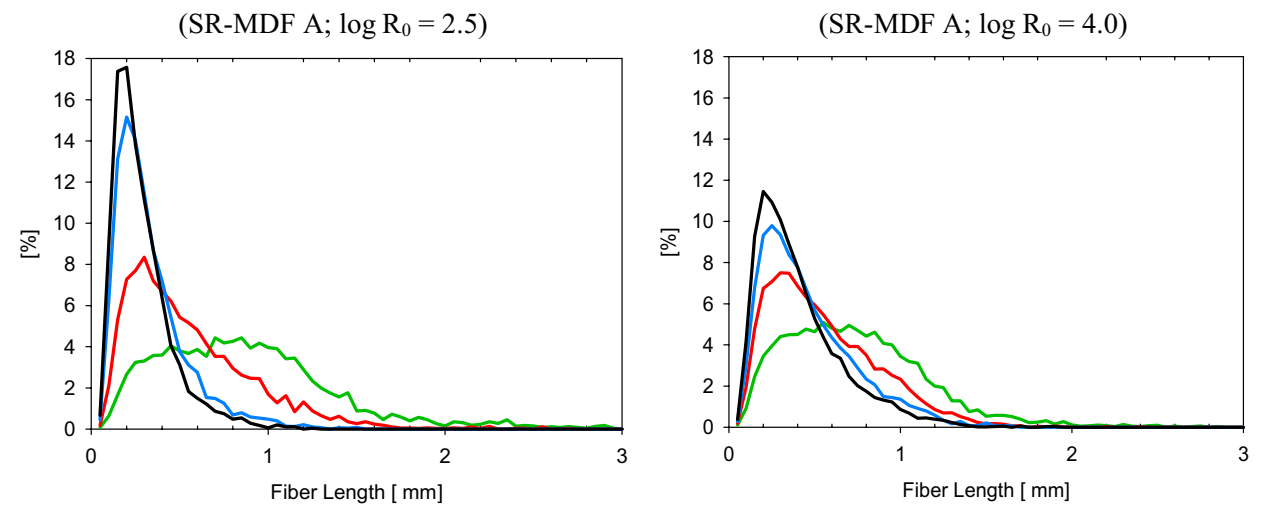

$\left(\mathrm{SR}-\mathrm{MDF} \mathrm{B} ; \log \mathrm{R}_{0}=2.5\right.$ )

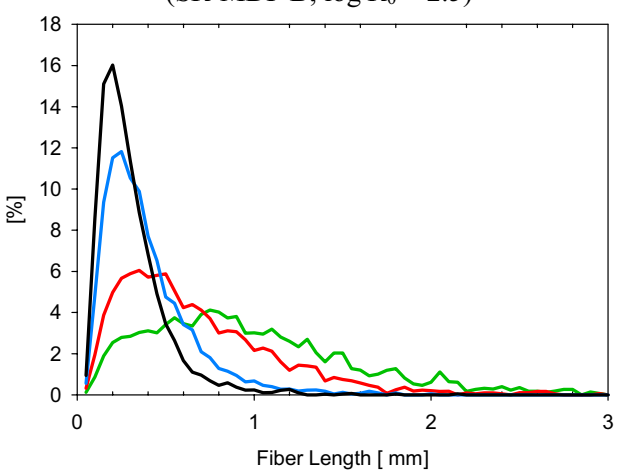

$\left(\mathrm{SR}-\mathrm{MDF} \mathrm{B} ; \log \mathrm{R}_{0}=4.0\right)$

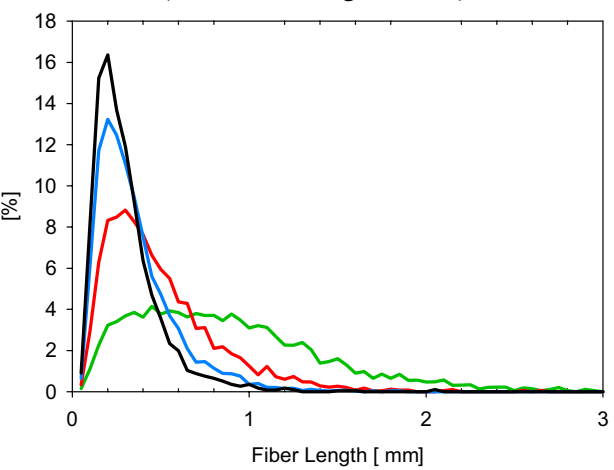

40 minutes additional beating 60 minutes additional beating

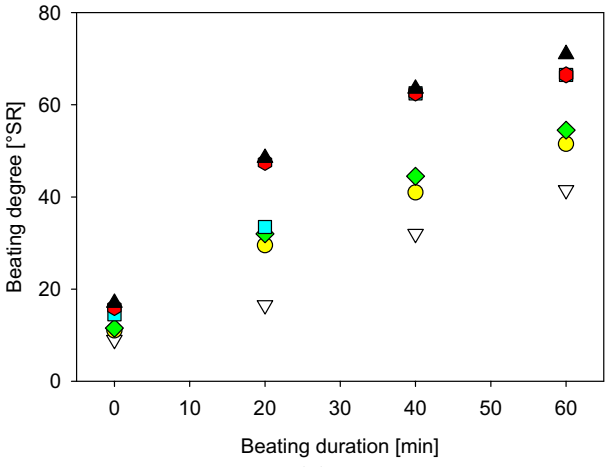

(a)

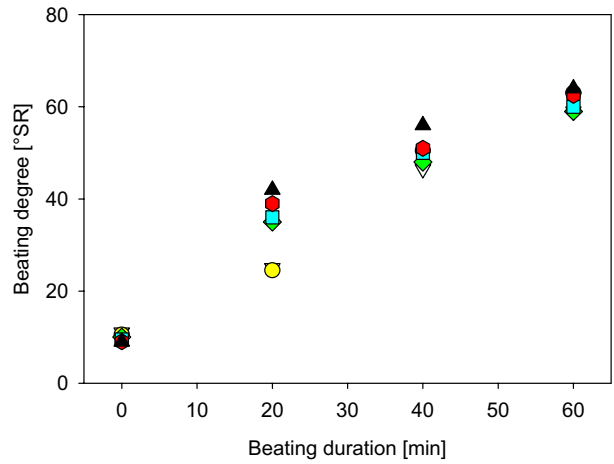

(b)

$\nabla \quad \log R_{0}=2.5 \quad \bigcirc \quad \log R_{0}=2.8 \quad \diamond \quad \log R_{0}=3.1$

$\square \quad \log R_{0}=3.4$

$\log R_{0}=3.7$

$\log R_{0}=4.0$

important parameter for comparison of different pulps. As expected, for all samples the beating degree increased with the beating duration. The beating degree of SR-MDF A treated at the lowest severity increased from $9{ }^{\circ} \mathrm{SR}$ without beating to $41.5^{\circ} \mathrm{SR}$ after $60 \mathrm{~min}$ of beating, while the beating degree of the same sample treated at the highest severity increased from $17^{\circ} \mathrm{SR}$ without additional beating to $71^{\circ} \mathrm{SR}$ after $60 \mathrm{~min}$ of beating. Therefore, the beating degree resulting from the same beating duration increased with the severity of the steaming treatment, indicating changes in the structural behavior of the fibers following different treatment severities. This effect is less pronounced in sample SR-MDF B, in which the beating degree of all samples was measured to be around $10{ }^{\circ} \mathrm{SR}$ without additional beating, and the beating degree after $60 \mathrm{~min}$ of beating ranges from $59{ }^{\circ} \mathrm{SR}$ at the lowest severity to $64{ }^{\circ} \mathrm{SR}$ at the highest severity treatment. In accordance with the findings for the fiber length distribution, the treatment severity did not 
significantly influence the beating degree resulting from the beating duration, except for the samples beaten for $20 \mathrm{~min}$, in which a gap of $17{ }^{\circ} \mathrm{SR}$ between the samples treated at the highest and lowest severity was measured.

\section{Paper Strength Properties}

Hand sheet testing can be used to gain information about the potential contribution of a given pulp to the strength of the final paper product. In Table 4 the paper strength properties of the measured test sheets of SR-MDF (A) and (B) are presented. In general, the paper strength properties of the steam refined waste MDF fibers were improved by intense beating and the highest strength properties could be realized at high beating degrees. However, as the beating degree is a measurement of the drainability of a fiber web, this reduction in dewatering capability leads to a reduction in paper machine speed [40]. In practice, a compromise between the drainability and the paper strength has to be found, and paper strength is usually compared at a similar beating degree.
One of the major functions of a packaging material is the protection of its content during transportation. For this, the ability to endure compressive forces is especially important, as it is a measure of its stacking strength [69]. The stacking strength of a corrugated board box is greatly influenced by the edgewise compression strength (ECT) and the flexural stiffness [70]. As there is a direct relationship between the ECT of a corrugated board and the compression strength of the individual parts [71, 72], the compression strength of the liner and flute, measured either by the Ring-CrushTest (RCT) or by the Short-Compression-Test (SCT), can be used to assess the suitability of a given paper substrate for corrugated boards. In this study the SCT was used to determine the compression strength, as the SCT is reported to show a better correlation to ECT than the RCT [73, 74]. In a field study, Adamopoulos et al. [75] have evaluated 16 different recycled liners and 7 different corrugating recycledmediums and have found an average Compression Index (CI) in machine direction of 28.8 and $30.8 \mathrm{~N} \mathrm{~m} \mathrm{~g}^{-1}$ and an average $\mathrm{CI}$ in cross direction of 15.3 and $17.3 \mathrm{~N} \mathrm{~m} \mathrm{~g}^{-1}$,

Table 4 Paper strength properties of SR-MDF (A) and SR-MDF (B)

\begin{tabular}{|c|c|c|c|c|c|c|c|c|}
\hline \multirow{2}{*}{$\begin{array}{l}\text { Treatment } \\
\text { severity }\end{array}$} & \multicolumn{4}{|l|}{ SR-MDF (A) } & \multicolumn{4}{|l|}{ SR-MDF (B) } \\
\hline & Beating degree & $\begin{array}{l}\text { Compression- } \\
\text { Index }\end{array}$ & Tensile-Index & Tear-Index & Beating degree & $\begin{array}{l}\text { Compression- } \\
\text { Index }\end{array}$ & Tensile-Index & Tear-Index \\
\hline$\left(\log \mathrm{R}_{0}\right)$ & $\left({ }^{\circ} \mathrm{SR}\right)$ & $(\mathrm{Nm} / \mathrm{g})$ & $(\mathrm{Nm} / \mathrm{g})$ & $\left(\mathrm{mN}^{*} \mathrm{~m}^{2} / \mathrm{g}\right)$ & $\left({ }^{\circ} \mathrm{SR}\right)$ & $(\mathrm{Nm} / \mathrm{g})$ & $(\mathrm{Nm} / \mathrm{g})$ & $\left(\mathrm{mN}^{*} \mathrm{~m}^{2} / \mathrm{g}\right)$ \\
\hline \multirow[t]{4}{*}{2.5} & 9.0 & - & 1.2 & 0.6 & 11.0 & - & 2.5 & 0.7 \\
\hline & 16.5 & 10.6 & 5.6 & 0.6 & 25.0 & - & 6.4 & 0.8 \\
\hline & 32.0 & 11.3 & 5.3 & 0.7 & 46.5 & - & 6.0 & 0.7 \\
\hline & 41.5 & 14.0 & 6.8 & 0.7 & 59.0 & 17.5 & 11.3 & 1.0 \\
\hline \multirow[t]{4}{*}{2.8} & 11.0 & - & 3.7 & 0.9 & 10.5 & - & 2.6 & 0.7 \\
\hline & 29.5 & 11.2 & 7.4 & 0.8 & 24.5 & - & 7.3 & 0.8 \\
\hline & 41.0 & 13.2 & 10.1 & 0.8 & 50.5 & 11.8 & 7.6 & 0.8 \\
\hline & 51.5 & 14.7 & 12.7 & 0.8 & 63.0 & 15.6 & 10.4 & 0.8 \\
\hline \multirow[t]{4}{*}{3.1} & 11.5 & - & 4.2 & 0.9 & 10.0 & - & 2.2 & 0.9 \\
\hline & 32.0 & 12.3 & 9.1 & 0.8 & 35.0 & - & 3.7 & 0.8 \\
\hline & 44.5 & 15.5 & 11.6 & 0.8 & 48.0 & 12.3 & 6.4 & 0.8 \\
\hline & 54.5 & 17.8 & 13.0 & 0.8 & 59.0 & 15.2 & 10.2 & 0.8 \\
\hline \multirow[t]{4}{*}{3.4} & 14.5 & 9.7 & 4.5 & 1.0 & 9.5 & - & 2.7 & 0.8 \\
\hline & 33.5 & 17.3 & 11.8 & 1.0 & 36.0 & 11.7 & 6.5 & 0.9 \\
\hline & 62.5 & 20.4 & 18.0 & 1.1 & 50.0 & 14.3 & 10.0 & 0.8 \\
\hline & 66.5 & 22.4 & 22.2 & 1.3 & 60.0 & 16.1 & 11.4 & 0.9 \\
\hline \multirow[t]{4}{*}{3.7} & 16.0 & 11.2 & 8.8 & 1.4 & 9.0 & - & 1.2 & 0.7 \\
\hline & 47.5 & 20.6 & 22.8 & 1.9 & 39.0 & 15.0 & 7.1 & 0.9 \\
\hline & 62.5 & 25.1 & 29.2 & 1.7 & 51.0 & 16.9 & 9.5 & 0.9 \\
\hline & 66.5 & 27.7 & 32.8 & 1.8 & 62.5 & 16.0 & 10.9 & 0.8 \\
\hline \multirow[t]{4}{*}{4.0} & 17.0 & 9.9 & 7.6 & 1.3 & 9.0 & - & 1.6 & 0.7 \\
\hline & 48.5 & 19.4 & 21.3 & 1.7 & 42.0 & 11.3 & 6.2 & 0.8 \\
\hline & 63.5 & 24.2 & 26.3 & 1.8 & 56.0 & 13.1 & 9.9 & 1.0 \\
\hline & 71.0 & 26.1 & 31.8 & 1.7 & 64.0 & 15.9 & 11.3 & 0.9 \\
\hline
\end{tabular}

Values marked as “-” were too low to be measurable 
respectively. The CI measured from the two recycled pulps gathered from industrial manufacturers of corrugated board production for comparison presented in Table 5 is found to be similar, ranging from 12.4 to $27.4 \mathrm{~N} \mathrm{~m} \mathrm{~g}^{-1}$. The $\mathrm{CI}$ of the SR-MDF (A) samples measured in this study range from roughly $10 \mathrm{~N} \mathrm{~m} \mathrm{~g}^{-1}$ at low beating degrees up to $27 \mathrm{~N} \mathrm{~m} \mathrm{~g}^{-1}$ at high beating degrees in combination with a high severity treatment, showing similar compression strength to recycled pulp currently found in industrial use. At a beating degree of roughly $35^{\circ} \mathrm{SR}$ for example, a CI of $17.3 \mathrm{~N} \mathrm{~m} \mathrm{~g}^{-1}$ was determined for the SR-MDF (A) sample treated with a severity of 3.4, falling between the CI of recycled pulp \#1 with $12.4 \mathrm{~N} \mathrm{~m} \mathrm{~g}^{-1}$ and recycled pulp \#2 with $21.2 \mathrm{~N} \mathrm{~m} \mathrm{~g}^{-} 1$.

The tensile and tear strength achievable with the SR-MDF samples are low in comparison to the paper strengths of the two recycled pulps. The steaming of the wood in the TMP process of the MDF production is done at temperatures ranging from 160 to $180^{\circ} \mathrm{C}$ for a duration of 3 to $6 \mathrm{~min}$ [1]. This steaming leads to a softening of the lignin as the glass transition point is exceeded and an ensuing coating of the fiber surface with lignin, which hinders the defibrillation in the subsequent refining [55]. However, steam treatment of higher severities are reported to lead to softening of the fibers and an increased flexibility [76, 77], which can be advantageous in the subsequent refining steps. Distinct differences in the influence of the steam treatment severity on the achievable paper strengths between the two steam treated waste MDF samples were observable. For the SRMDF (A) sample, a higher treatment severity had a positive effect on the paper strength, leading to higher paper strength at the same beating degree in most cases. The SR-MDF (B) sample saw no influence of treatment severity on the resulting paper strength, reflecting the unchanged fiber morphology described in Sect. 3.1. While at a low severity of 2.5 the achievable paper strength of the two SR-MDF samples does not differ greatly, a substantial higher paper strength could be achieved using the SR-MDF (A) sample treated at high severities. As the two sample sets underwent the exact same treatment and evaluation processes, the differences in response to the steam treatment must be caused by differences in the two MDF sample sets.
The different behavior of the two samples might be explainable with a differing amount of softwood and hardwood fibers in the sample. Due to the carbohydrate compositions (Table 1), the fiber dimensions (Table 2), and the high amount of acetic acid found in the liquid phase after steaming of sample SR-MDF (A) [18], a higher content of hardwood in sample SR-MDF (A) was concluded. However, generally a high amount of softwood fibers in the pulp correlates positive with the compression and tensile strength of the produced paper due to the higher fiber length [58, 75], and thus higher paper strengths could be expected for sample SR-MDF (B). One possible explanation for the low influence of the steaming treatment on the fiber and paper properties of SR-MDF (B) could be a less intense autohydrolysis of the main components in the steam treatment due to the lower amount of acetyl groups in softwood. The reduced autohydrolysis might lead to a lower flexibility of the fibers of SR-MDF (B) in comparison to SR-MDF (A). Another difference between softwoods and hardwoods is the reaction of lignin constituents under steam treatment. Guaiacyl lignin, which makes up the majority of the lignin found in softwood, is prone to condensation reactions [78, 79], and a high degree of lignin repolymerization might decrease the flexibility of the fibers. The potential effect of lignin repolymerization, might be overcome by the addition of condensation inhibitors such as 2-naphtol, which might be advantageous. Another aspect to look into is the addition of mineral acids in the steaming of waste MDF samples with a high share of softwood to compensate for the lower amount of acetyl-groups. The effect of raw material composition and process conditions of the MDF production on the subsequent recycling deserves further attention.

\section{Optical Properties}

The severity of the steaming treatment shows a direct influence on the coloration of the fibrous material and the produced test sheets as presented in Fig. 4. At higher severities, a distinctively darker shade of brown can be observed with the eye than at lower severities, while no differences between SR-MDF (A) and SR-MDF (B) were discernible.
Table 5 Paper strength properties of recycled pulp gathered from two different industrial corrugated paperboard producers

\begin{tabular}{llllll}
\hline & $\begin{array}{l}\text { Beating duration } \\
(\mathrm{min})\end{array}$ & $\begin{array}{l}\text { Beating degree } \\
\left({ }^{\circ} \mathrm{SR}\right)\end{array}$ & $\begin{array}{l}\text { Compression-Index } \\
(\mathrm{Nm} / \mathrm{g})\end{array}$ & $\begin{array}{l}\text { Tensile-Index } \\
(\mathrm{Nm} / \mathrm{g})\end{array}$ & $\begin{array}{l}\text { Tear-Index } \\
\left(\mathrm{mN}^{*} \mathrm{~m}^{2} / \mathrm{g}\right)\end{array}$ \\
\hline Recycled pulp \#1 & 0 & 37.0 & 12.4 & 19.6 & 5.8 \\
& 2 & 53.5 & 17.0 & 28.5 & 5.2 \\
& 4 & 61.5 & 18.3 & 30.6 & 4.5 \\
Recycled pulp \#2 & 0 & 18.0 & 12.8 & 14.1 & 5.5 \\
& 2 & 37.5 & 21.2 & 34.2 & 8.1 \\
& 8 & 54.5 & 25.2 & 46.5 & 6.2 \\
& 10 & 61.5 & 27.4 & 50.9 & 5.7 \\
\hline
\end{tabular}


Fig. 4 Testsheets made out of SR-MDF (A) without additional beating steam treated at severities of $2.5,2.8,3.1,3.4,3.7$ and 4.0 (from left to right)

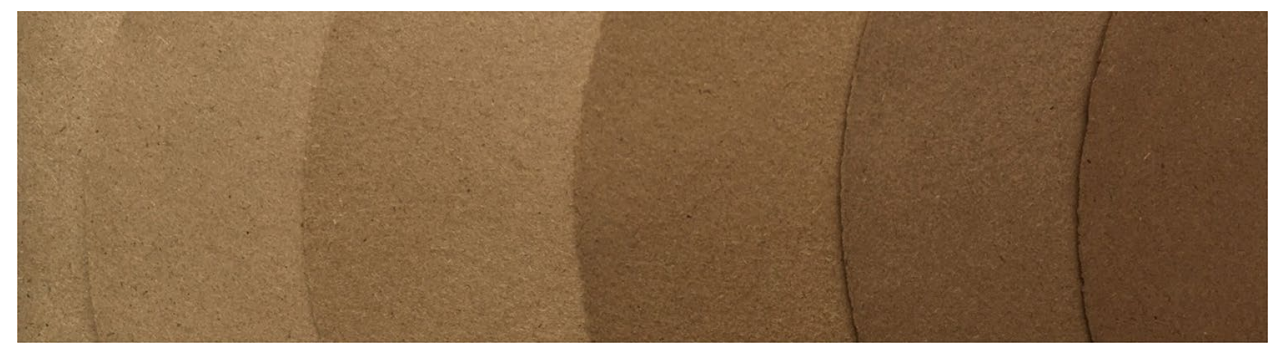

Besides the shade of brown, the severity of the steam treatment also influenced the brightness of the test sheets, with higher severity treatments leading to a lower brightness value, as presented in Fig. 5. A slight increase in measured brightness following more intense beating can be observed for both MDF samples, irrespective of treatment severity. The brightness values for SR-MDF (B) and for SR-MDF (A) do not differ considerable, ranging from around $10 \%$ for high severity treatments up to around $27 \%$ for low severity treatments.

The darkening and the loss of brightness of steam treated fibers has been reported before $[76,77]$ and can be attributed to the creation of chromophoric groups in the lignin following condensation and oxidation reactions [80]. However, the low brightness and dark brown hue of the waste MDF fibers should not be detrimental to the application in packaging material if used in the central layers of linerboard or in the flute, as their optical properties play a subordinated role.

\section{Conclusion}

Distinct differences in response to the refining treatment between the two steam treated waste MDF samples were found. An increase in treatment severity had a positive effect on the paper making quality of the SR-MDF (A) fibers, while no such influence could be found for the fibers of
SR-MDF (B). The explanation might be differences in the share of hardwood and softwood in the waste MDF samples concluded from the chemical composition. While it was possible to produce fibers with comparable compression strength to recycled pulp from the sample SR-MDF (A), the paper strengths achievable from sample SR-MDF (B) were lacking. From these findings it can be concluded that the composition of the waste MDF raw material does not only influence the chemical interactions during the steaming process [18], but also the papermaking quality of the resulting pulp. Consequentially, intimate knowledge of the waste MDF composition is needed for process optimization and will likely play a key role in successful valorization. Additionally, the surface of MDF is often laminated using thermoplastic polymers which tend to melt in high moisture and high temperature environment such as the steam treatment presented in this study. Thus, efficient sorting will be of substantial importance.

Although the tensile and tear strength of the test sheets produced from the MDF (A) samples were not as high as the ones produced from the recycled pulp utilized in industry, a comparable compressive strength was determined. This is the one of the most important properties for application in corrugated board packaging. Using the information provided in this study as a basis, optimization of the processes might further improve the attainable paper strengths. Besides the attainable paper strengths, the final price of the steam treated
Fig. 5 Influence of treatment severity and beating duration on the brightness of test sheets made from SR-MDF (A) (a) and SR-MDF (B) (b)

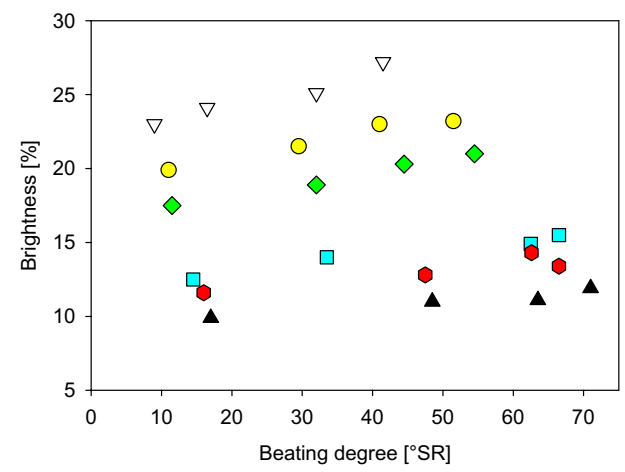

(a)

$\nabla \quad \log R_{0}=2.5 \quad \bigcirc \quad \log R_{0}=2.8$ $\log R_{0}=3.1$

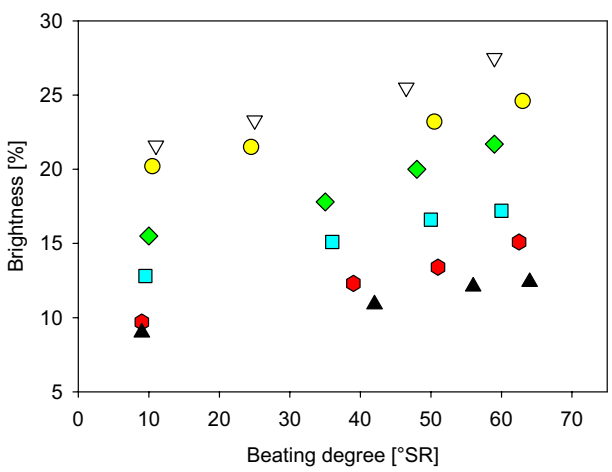

(b) 
waste MDF fibers in comparison to recycling pulp will be of great importance for a potential utilization, as the fiber material used for the flute of paperboard packaging is a bulk product and often considered filler material. Given favorable environmental policy and legislative changes, steam treated waste MDF fibers might find application in corrugating medium or the test liner middle ply as outlined in this study, enabling an extension of the waste material cascade.

Acknowledgements A special thank you goes to Mark Irle from Ècole supérieure du bois (Nantes, France) for supplying the MDF material.

Author Contributions All authors have read and agree to the published version of the manuscript. Conceptualization, SH and BS; methodology, $\mathrm{SH}$; formal analysis, $\mathrm{SH}$ and JJ; experimental investigation, $\mathrm{SH}$ and JJ; writing — original draft preparation, $\mathrm{SH}$; writing - review and editing, SH, JJ, GC and BS; visualization, SH; supervision, BS; project administration and funding acquisition, BS.

Funding Open Access funding enabled and organized by Projekt DEAL. This research was performed in the project "FLEXIBI" funded in the program FACCE SURPLUS 2 by the PTJ, BMBF based on a decision of the German Parliament, grant number 031B0610.

Data Availability Experimental material is not available from the authors.

\section{Compliance with Ethical Standards}

Conflict of interest The authors declare no conflict of interest.

Open Access This article is licensed under a Creative Commons Attribution 4.0 International License, which permits use, sharing, adaptation, distribution and reproduction in any medium or format, as long as you give appropriate credit to the original author(s) and the source, provide a link to the Creative Commons licence, and indicate if changes were made. The images or other third party material in this article are included in the article's Creative Commons licence, unless indicated otherwise in a credit line to the material. If material is not included in the article's Creative Commons licence and your intended use is not permitted by statutory regulation or exceeds the permitted use, you will need to obtain permission directly from the copyright holder. To view a copy of this licence, visit http://creativecommons.org/licenses/by/4.0/.

\section{References}

1. Deppe, H.-J., Ernst, K.: MDF - Mitteldichte Faserplatten. Leinfelden-Echterdingen, DRW-Verl (1996)

2. Irle, M., Barbu, M.C., Reh, R., Bergland, L., Rowell, R.: Wood composites. In: Rowell, R.M. (ed.) Handbook of Wood Chemistry and Wood Composites, 2nd edn., pp. 321-412. CRC Press, Boca Raton (2012)

3. European Panel Federation: Annual Report 2015-2016 (2016)

4. FAO. FAO STAT: Forestry production and trade. http://www.fao. org/faostat/en/\#data/FO. Accessed 24 March 2020

5. Leslie, D., Reimer, S.: Fashioning furniture: restructuring the furniture commodity chain. Area 35, 427-437 (2003). https://doi.org /10.1111/j.0004-0894.2003.00192.x
6. Irle, M., Privat, F., Couret, L., Belloncle, C., Déroubaix, G., Bonnin, E., Cathala, B.: Advanced recycling of post-consumer solid wood and MDF. Wood Mat. Sci. Eng. 11, 1-5 (2018). https://doi. org/10.1080/17480272.2018.1427144

7. Garcia, C.A., Hora, G.: State-of-the-art of waste wood supply chain in Germany and selected European countries. Waste Manag. 70, 189-197 (2017). https://doi.org/10.1016/j.wasma n.2017.09.025

8. DIRECTIVE 2008/98/EC OF THE EUROPEAN PARLIAMENT AND OF THE COUNCIL of 19 November 2008 on waste and repealing certain Directives (2008)

9. Sokka, L., Koponen, K., Keränen, J.: Cascading use of wood in Finland - with comparison to selected EU countries (2015)

10. Lubis, M.A.R., Hong, M.-K., Park, B.-D.: Hydrolytic removal of cured urea-formaldehyde resins in medium-density fiberboard for recycling. J. Wood Chem. Technol. 38, 1-14 (2018). https ://doi.org/10.1080/02773813.2017.1316741

11. Kraft, R.: Zur chemisch-technologischen Verwertung von gebrauchten Holzwerkstoffen und Holzrinden. Göttingen, Cuvillier (2007)

12. Franke, R., Roffael, E.: Zum recycling von span- und MDFplatten. Holz als Roh- und Werkstoff 56, 79-82 (1998). https:// doi.org/10.1007/s001070050268

13. Fleischer, O., Marutzky, R.: Hydrolyse von Harnstoff-Formaldehyd-Harzen: Auflsung des Spangefges in Holzwerkstoffen durch hydrolytischen Abbau der Leimfuge. Holz als Roh- und Werkstoff 5, 295-300 (2000)

14. Roffael, E., Hüster, H.-G.: Complex chemical interactions on thermo hydrolytic degradation of urea formaldehyde resins (UF-resins) in recycling UF-bonded boards. Eur. J. Wood Wood Prod. 70, 401-405 (2012). https://doi.org/10.1007/s0010 7-011-0574-7

15. Mantanis, G.I., Athanassiadou, E.T., Barbu, M.C., Wijnendaele, K.: Adhesive systems used in the European particleboard, MDF and OSB industries. Wood Mater. Sci. Eng. 13, 104-116 (2018). https://doi.org/10.1080/17480272.2017.1396622

16. Overend, R.P., Chornet, E., Gascoigne, J.A.: Fractionation of lignocellulosics by steam-aqueous pretreatments [and discussion]. Philos. Trans. R. Soc. A 321, 523-536 (1987). https://doi. org/10.1098/rsta.1987.0029

17. Chornet, E.; Overend, R.P.: Phenomological kinetics and reaction engineering aspects of steam/aqueous treatments. In: Focher, B., Marzetti, A., Crescenzi, V., (eds.) Steam Explosion Techniques: Fundamentals and Industrial Applications. Proceedings of the International Workshop on Steam Explosion Techniques: Fundamentals and Industrial Applications, pp 22-58. Gordon and Breach Science Publishers, Milan, Italy, 20-21 October 1988. ISBN 9782881244575 (1991)

18. Hagel, S., Saake, B.: Fractionation of waste MDF by steam refining. Molecules 25, 2165 (2020). https://doi.org/10.3390/molec ules25092165

19. Moezzipour, B., Ahmadi, M., Abdolkhani, A., Doosthoseini, K.: Chemical changes of wood fibers after hydrothermal recycling of MDF wastes. J. Indian Acad. Wood Sci. 14, 133-138 (2017). https ://doi.org/10.1007/s13196-017-0198-6

20. Roffael, E., Behn, C., Schneider, T., Krug, D.: Bonding of recycled fibres with urea-formaldehyde resins. Int. Wood Prod. J. 7, 36-45 (2016). https://doi.org/10.1080/20426445.2015.1131918

21. Roffael, E., Dix, B., Behn, C., Bär, G.: Mitverwendung von UFHarz-gebundenen Gebrauchtspan- und -faserplatten in der MDFHerstellung. Eur. J. Wood Wood Prod. 68, 121-128 (2010). https ://doi.org/10.1007/s00107-009-0376-3

22. Roffael, E., Dix, B., Behn, C., Bär, G.: IR-Spektren von TMP und CTMP, hergestellt aus Kiefernholz und mitteldichten Faserplatten (MDF). Eur. J. Wood Prod. 67, 233-235 (2009). https://doi. org/10.1007/s00107-009-0314-4 
23. Lubis, M.A.R., Hong, M.-K., Park, B.-D., Lee, S.-M.: Effects of recycled fiber content on the properties of medium density fiberboard. Eur. J. Wood Prod. 76, 1515-1526 (2018). https://doi. org/10.1007/s00107-018-1326-8

24. Petar Antov: Possibilities for manufacturing eco-friendly medium density fibreboards from recycled fibres -a review. In: Procedings of the 30th International Conference on Wood Science and Technology - ICWST 2019 "IMPLEMENTATION OF WOOD SCIENCE IN WOODWORKING SECTOR" and 70th anniversary of Drvna industrija Journal

25. Moezzipour, B., Abdolkhani, A., Doost-hoseini, K., Ahmad Ramazani, S.A., Tarmian, A.: Practical properties and formaldehyde emission of medium density fiberboards (MDFs) recycled by electrical method. Eur. J. Wood Wood Prod. 76, 1287-1294 (2018). https://doi.org/10.1007/s00107-018-1291-2

26. Couret, L., Irle, M., Belloncle, C., Cathala, B.: Extraction and characterization of cellulose nanocrystals from post-consumer wood fiberboard waste. Cellulose 24, 2125-2137 (2017). https:// doi.org/10.1007/s10570-017-1252-7

27. Gu, J., Hu, C., Zhong, R., Tu, D., Yun, H., Zhang, W., Leu, S.-Y.: Isolation of cellulose nanocrystals from medium density fiberboards. Carbohydr. Polym. 167, 70-78 (2017). https://doi. org/10.1016/j.carbpol.2017.02.110

28. Chaharmahali, M., Tajvidi, M., Najafi, S.K.: Mechanical properties of wood plastic composite panels made from waste fiberboard and particleboard. Polym. Compos. 29, 606-610 (2008). https:// doi.org/10.1002/pc.20434

29. Bütün, F.Y., Sauerbier, P., Militz, H., Mai, C.: The effect of fibreboard (MDF) disintegration technique on wood polymer composites (WPC) produced with recovered wood particles. Compos. A Appl. Sci. Manuf. 118, 312-316 (2019). https://doi.org/10.1016/j. compositesa.2019.01.006

30. Bütün, F.Y., Mayer, A.K., Ostendorf, K., Gröne, O.-E.Z., Krause, K.C., Schöpper, C., Mertens, O., Krause, A., Mai, C.: Recovering fibres from fibreboards for wood polymer composites production. Int. Wood Prod. J. 52, 1-8 (2018). https://doi.org/10.1080/20426 445.2018.1462965

31. Zhao, J., Tian, D., Shen, F., Hu, J., Zeng, Y., Huang, C.: Valorizing waste lignocellulose-based furniture boards by phosphoric acid and hydrogen peroxide (Php) pretreatment for bioethanol production and high-value lignin recovery. Sustainability 11, 6175 (2019). https://doi.org/10.3390/su11216175

32. Kang, Y.-R., Hwang, J.-S., Bae, K.-H., Cho, H.-H., Lee, E.-J., Cho, Y.-S., Nam, K.-D.: Pretreatment and enzymatic saccharification of wasted MDF for bioethanol production. KSBB J. 30, 332-338 (2015). https://doi.org/10.7841/ksbbj.2015.30.6.332

33. Kang, Y.-R., Hwang, J.-S., Bae, K.-H., Cho, H.-H., Lee, E.-J., Cho, Y.-S., Nam, K.-D.: Bioethanol production by using wasted MDF. KSBB J. 31, 73-78 (2016). https://doi.org/10.7841/ksbbj .2016.31.1.73

34. Park, Y.-K., Park, K.-S., Park, S.H.: Fast pyrolysis of mediumdensity fiberboard using a fluidized bed reactor. Appl. Chem. Eng. 24, 672-675 (2013). https://doi.org/10.14478/ace.2013.1099

35. Park, K.S., Kang, H.K., Park, S.H., Jung, S.-C., Jeon, J.-K., Lee, I.-G., Kim, S.C., Park, Y.-K.: Conversion of waste medium density fiberboard over SAPO-11 catalyst. J. Nanoelectron. Optoelectron. 8, 561-564 (2013). https://doi.org/10.1166/jno.2013.1527

36. Jin, B.-B., Heo, H.S., Ryu, C., Kim, S.-S., Jeon, J.-K., Park, Y.-K.: The copyrolysis of block polypropylene with particle board and medium density fiber. Energy Sour. A 36, 958-965 (2014). https ://doi.org/10.1080/15567036.2010.551263

37. Han, T.U., Kim, Y.-M., Watanabe, C., Teramae, N., Park, Y.-K., Kim, S., Lee, Y.: Analytical pyrolysis properties of waste medium-density fiberboard and particle board. J. Ind. Eng. Chem. 32, 345-352 (2015). https://doi.org/10.1016/j.jiec.2015.09.008
38. Czarnecki, R., Dziurka, D., Lecka, J.: The use of recycled boards as the substitute for particles in the centre layer of particleboards. Electron. J. Pol. Agric. Univ. 06, 1 (2003)

39. Beele, P.: Demonstration of end uses for recovered MDF fibre. Final report. http://www.mdfrecovery.co.uk/wordpress/wp-conte nt/uploads/2015/02/WRAP-MDF_Recycling_-_demonstration_ of_end_uses.pdf (2009). Accessed 26 Jan 2021

40. Twede, D., Selke, S.E.M., Kamdem, D.-P., Shires, D.B.: Cartons, Crates and Corrugated Board. Handbook of Paper and Wood Packaging Technology, 2nd edn. DEStech Publications, Lancaster (2015)

41. VDW. Jahresbericht der Wellpappenindustrie 19/20. https://www. wellpappen-industrie.de/verband/publikationen/jahresbericht.html (2020). Accessed 15 July 2020

42. Kirwan, M.J.: Handbook of Paper and Paperboard Packaging Technology. John Wiley \& Sons Ltd, Oxford (2013)

43. Verband der Wellpappen-Industrie e.V. Zahlen und Fakten. Daten für die Wellpappenindustrie (2020)

44. Kramer, J: Wood fiber supply - enough to match pulp and paper demand? In Pulping Conference Book 2. Pulping Conference, Montreal, Quebec, Canada, 25-29.10; TAPPI, Ed.; TAPPI Press: Atlanta, Georgia, USA (1998)

45. Dominic, C., Östlund, S., Buffington, J., Masoud, M.M.: Towards a conceptual sustainable packaging development model: a corrugated box case study. Package Technol. Sci. 28, 397-413 (2015). https://doi.org/10.1002/pts.2113

46. Nazhad, M.: Recycled fiber quality - a review. J. Ind. Eng. Chem. 11, 314-329 (2005)

47. Nazhad, M.M.: Fundamentals of strength loss in recycled paper (1994).

48. Hubbe, M., Venditti, R., Rojas, O.: What happens to cellulosic fibers during papermaking and recycling? A review. BioResources 2, 739-788 (2007)

49. Howard, R.C., Bichard, W.: The basic effects of recycling on pulp properties. MRS Proc. 266, 195 (1992). https://doi.org/10.1557/ PROC-266-195

50. Hubbe, M.A., Zhang, M.: Recovered kraft fibers and wet-end dry-strength polymers. In: Proceedings of the practical papermakers conference. Practical Papermakers Conference; TAPPI, Ed.; TAPPI Press: Atlanta, Georgia, USA (2005)

51. Laivins, G.V., Scallan, A.M.: The mechanism of hornification of wood pulps. In: Proceedings of the 10th Fundamental Research Symposium. 10th Fundamental Research Symposium, Oxford, United Kingdom; FRC: Bury Lancashire (1993)

52. Salehi, K., Kordsachia, O., Saake, B.: the potential of what straw high yield MEA pulp for enhancing strength properties of recycled paper. BioResources 12, 8255-8271 (2017)

53. Aravamuthan, R., Greaves, J.: The effect of multiple recycled on wheat straw fibers. In: Proceedings of the Pulping Conference Book 2. Pulping Conference, Montreal, Quebec, Canada, 25-29.10; TAPPI, Ed.; TAPPI Press: Atlanta, Georgia, USA (1998)

54. Berthold, D., Meinlschmidt, P., Ritter, N.: Hardwood processing in Germany: challenges and opportunities for the wood based panel indsutry. In: Möttönen, V., Heinonen, E. (eds.) Proceedings of the 6th International Scientific Conference on Hardwood Processing, pp 97-108. Natural Resources Institute Finland: Helsinki. ISBN 978-952-326-509-7 (2017)

55. Fengel, D., Wegener, G.: Wood. Chemistry, Ultrastructure, Reactions. Walter de Gruyter, Berlin (1983)

56. Macdonald, R.G., Franklin, J.N.: Papermaking and Paperboard Making, 2nd edn. McGraw-Hill, New York (1970)

57. Gharehkhani, S., Sadeghinezhad, E., Kazi, S.N., Yarmand, H., Badarudin, A., Safaei, M.R., Zubir, M.N.M.: Basic effects of pulp refining on fiber properties-a review. Carbohydr. Polym. 115, 785-803 (2015). https://doi.org/10.1016/j.carbpol.2014.08.047 
58. Niskanen, K.: Paper Physics, 2, totally updated ed.; Paperi ja Puu Oy: Helsinki, 2008, ISBN 9789525216295.

59. DIN 54360:2004-07, Faserstoff_- Labormahlung_- Jokro-MühleVerfahren. Beuth Verlag GmbH: Berlin

60. DIN EN ISO 5263-2:2004-12, Faserstoffe_- Nassaufschlagen im Labor_- Teil_2: Aufschlagen von Holzstoff bei 20_ ${ }^{\circ} \mathrm{C}$ (ISO_52632:2004); Deutsche Fassung EN_ISO_5263-2:2004. Beuth Verlag $\mathrm{GmbH}$, Berlin.

61. DIN EN ISO 5267-1:2000-10, Faserstoffe_- Bestimmung des Entwässerungsverhaltens_- Teil_1: Schopper-Riegler-Verfahren (ISO_5267-1:1999); Deutsche Fassung EN_ISO_5267-1:2000. Beuth Verlag GmbH: Berlin

62. DIN EN ISO 5269-2:2005-03, Faserstoffe_- Laborblattbildung für physikalische Prüfungen_- Teil_2: Rapid-Köthen-Verfahren (ISO_5269-2:2004); Deutsche Fassung EN_ISO_5269-2:2004. Beuth Verlag GmbH: Berlin

63. Technical Associatin of the Pulp and Paper Industry. Diffuse Brightness of Paper, Paperboard and Pulp (d/0); TAPPI Press: Atlanta, Georgia, USA (T 525 om-17) (2017)

64. DIN 54518:2004-03, Prüfung von Papier und Pappe_- Streifenstauchwiderstand. Beuth Verlag GmbH: Berlin

65. DIN EN ISO 1924-2:2009-05, Papier und Pappe_- Bestimmung von Eigenschaften bei Zugbeanspruchung_- Teil_2: Verfahren mit konstanter Dehngeschwindigkeit (20_mm/min) (ISO_19242:2008); Deutsche Fassung EN_ISO_1924-2:2008; Beuth Verlag $\mathrm{GmbH}$ : Berlin

66. DIN EN ISO 1974:2012-09, Papier_- Bestimmung des Durchreißwiderstandes_- Elmendorf Methode (ISO_1974:2012); Deutsche Fassung EN_ISO_1974:2012. Beuth Verlag GmbH: Berlin

67. Physical Testing of Pulp Handsheets (T 220 sp-01). TAPPI Press: Atlanta, Georgia, USA (2001)

68. Suchsland, O., Woodson, G.: Fiberboard Manufacturing Practices in the United States. Agriculture Handbook No. 640. U.S. Department of Agriculture Forest Service, Virginia (1987)

69. Frank, B.: Corrugated box compression-a literature survey. Packag. Technol. Sci. 27, 105-128 (2014). https://doi. org/10.1002/pts.2019

70. McKee, R.C., Gander, J.W: Study of the dominant factors of box compression strength. Part II, Verification of the simplified formula for top-load compression strength of commercial boxes. preliminary report to the Technical Committee of the Fourdrinier Kraft Board Institute. https://smartech.gatech.edu/bitstream/handl e/1853/1545/1108-4_000_01221962.pdf?sequence=1\&isAll owed=y (1962). Accessed 6 Aug 2020
71. Markström, H.: Testing methods and instruments for corrugated boards. Lorentzen \& Wettre: Kista (Suède), op. 1999, ISBN 9789197176538 (1999)

72. Whitsitt, W.: Compressive strength relaitonships and factors (1985)

73. Dimitrov, K., Heydenrych, M.: Relationship between the edgewise compression strength of corrugated board and the compression strength of liner and fluting medium papers. South. For. 71, 227-233 (2009). https://doi.org/10.2989/SF.2009.71.3.7.919

74. Iva Šarčević; Dubravko Banić; Diana Milčić: Evaluation of compressive test methods for paper using a mathematical model, based on compressive test for corrugated board. Acta Graphica 27, 47-50 (2017)

75. Adamopoulos, S., Martinez, E., Ramirez, D.: Characterization of packaging grade papers from recycled raw materials through the study of fibre morphology and composition. GlobalNEST Int. J. 9, 20-28 (2007). https://doi.org/10.30955/gnj.000384

76. Kokta, B.V., Ahmed, A.: Steam explosion pulping. In: Young, R.A., Akhtar, M. (eds.) Environmentally Friendly Technologies for the Pulp and Paper Industry, pp. 191-214. John Wiley, New York (1998)

77. Kokta, B.V.: Steam explosion pulping. In: Focher, B., Marzetti, A., Crescenzi, V. (eds.) Steam Explosion Techniques: Fundamentals and Industrial Applications : Proceedings of the International Workshop on Steam Explosion Techniques: Fundamentals and Industrial Applications, Gordon and Breach Science Publishers, Milan, Italy, 20-21 October 1988, pp. 163-206. ISBN 9782881244575 (1991)

78. Li, J., Gellerstedt, G., Toven, K.: Steam explosion lignins; their extraction, structure and potential as feedstock for biodiesel and chemicals. Bioresour. Technol. 100, 2556-2561 (2009). https:// doi.org/10.1016/j.biortech.2008.12.004

79. Shimizu, K., Sudo, K., Ono, H., Ishihara, M., Fujii, T., Hishiyama, S.: Integrated process for total utilization of wood components by steam-explosion pretreatment. Biomass Bioenergy 14, 195-203 (1998). https://doi.org/10.1016/s0961-9534(97)10044-7

80. Macdonald, R.G., Franklin, J.N.: The Pulping of Wood, 2nd edn. McGraw-Hill Book Company, New York (1969)

Publisher's Note Springer Nature remains neutral with regard to jurisdictional claims in published maps and institutional affiliations.

\section{Authors and Affiliations}

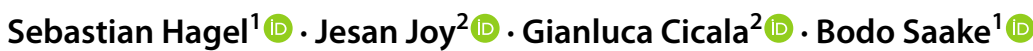

1 Institute of Wood Science, Chemical Wood Technology, Universität Hamburg, Haidkrugsweg 1, 22885 Barsbüttel, Germany
2 Department of Civil Engineering and Architecture, Università Degli Studi Ci Catania, Viale Andrea Doria 6, 95125 Catania, Italy 